\title{
Toprak Serilerinin Ayırt Edilmesinde NIRS Yansıma Tekniğinin Kullanım Olanaklarının Araştırılması
}

Investigation of The Possibilities of Using NIRS Reflection Technique for Detecting Soil Series Using Legacy Soil Data

\section{Yavuz Şahin TURGUT ${ }^{1^{*}}$}

\section{Suat ŞENOL ${ }^{2}$}

${ }^{1,2}$ Çukurova Üniversitesi Ziraat Fakültesi

Toprak Bilimi ve Bitki Besleme Bölümü/Adana

Sorumlu yazar: ysturgut@cu.edu.tr

0000-0002-8566-6375

0000-0002-6112-2621

*Yüksek lisans tezinden üretilmiştir

Gönderilme Tarihi:

Kabul Tarihi

11 Nisan 2020

20 Haziran 2020

\section{Özet}

Detaylı toprak etüt ve haritalama çalışmalarının toprak serileri ve fazlarının belirlenip haritalanması aşaması uzmanlık gerektiren ve zaman alan bir aşamadır. $\mathrm{Bu}$ nedenle, çalışmada toprak özelliklerinin belirlenmesinde son yıllarda kullanılmaya başlanılan NIRS yansıma tekniğinin toprak serilerini ayırt etmede kullanılabilirliğinin belirlenmesi amaçlanmıştır. Çukurova Bölgesi'nde haritalanmış toprak serileri ve önemli fazlarından burgu ile horizon esasına göre alınan 531 toprak örneğine ait yansıma değerleri elde edilmiştir. İstatistiksel analizler En Küçük Kısmi Kareler Regresyonu (EKKR) yöntemi Çapraz Doğrulama ve model tahmin yöntemi kullanılarak elde edilmiştir. Çapraz doğrulama sonucu kil için tüm veri setindeki 531 toprak örneğinin yansıma değerleri ile kalibrasyon arasındaki korelasyon katsayısı $\left(\mathrm{R}^{2}\right)$ değerleri; kil için 0,47 ; silt 0,44 ; kum 0,36 ; organik madde 0,32 ; kireç 0,21 bulunmuştur. Validasyon setinde ise $\mathrm{R}^{2}$ değerleri sirasılya; kil 0.44; silt 0.41 ; kum 0.29 , organik madde 0.26 ; kireç 0.18 olarak bulunmuştur. NIRS teknolojisinin, toprak serilerinin tanımlanması ve haritalanması aşamasında düşük korelasyon değerleri vermesi ve yansıma değerleri ile topraklar arasında sağlıklı ilişkiler bulunamaması 
nedeniyle başarısız olduğu görülmüştür.

Anahtar Kelimeler: Görünür-yakın kızı̈ötesi spektroskopi, toprak etüt ve haritalama, toprak serileri

\section{Abstract}

Determining and mapping of the soil series with their phases in the detailed soil survey studies is a time consuming and required highly specialization. Therefore, the aim of this study is to determine the usefulness of NIRS reflection technique in the discriminating of soil series in field due to this technique nowadays has been used in the determination of some soil properties. The reflection values of 531 soil samples taken on a horizon basis to present soil series and major phases of the Çukurova Region were obtained. Statistical analysis was performed using the PLSR method CV (Cross Validation) and model estimation method. As a result of cross-validation, $\mathrm{R}^{2}$ values between the reflection values and calibration of the soil sample 531 in the whole data set for clay; 0.47 for clay; 0.44 for silt; 0.36 for sand; 0.32 for organic matter; 0.21 for lime was found. In the validation set; clay $\mathrm{R}^{2} 0.44$; silt $\mathrm{R}^{2} 0.41$; sand $\mathrm{R}^{2}$ 0.29 , organic material $\mathrm{R}^{2} 0.26$; lime $\mathrm{R}^{2}$ was found to be 0.18 . It is concluded that NIRS technology was found to fail due to low correlation values in the identification and mapping of soil series and lack of healthy relationships between reflection values and soils.

Keywords: visible-near infrared spectroscopy, soil survey and mapping, soil series

\section{GíRiș}

20.yy'dan bugüne kadar artmakta olan dünya nüfusu, 1950'li yılların ilk yarısında yaklaşık 2,7 milyar iken, günümüzde ise bu rakam 7,2 milyardır ve daha da artmaktadır (Anonim, 2016). Dünyanın mevcut kıt kaynaklarını arttırmak pek mümkün değildir. Nitekim toprakların haritalanması ve en küçük toprak sınıflandırma birimlerini oluşturan serilerin kullanım amaçlarına uygun karakteristiklerinin belirlenebilmesi büyük önem arz etmektedir. Gerek arazi çalışmaları gerekse de laboratuvar çalışmaları aracılığıyla toprağa ait tekstür, nem içeriği, strüktür, kireç içeriği, toprak asitliği $(\mathrm{pH})$, renk, kıvam gibi fiziksel ve kimyasal özelliklerin belirlenebilirliği klasik yöntemlerle oldukça zaman alıc1, maliyetli ve güçtür (Rossel, 2008). Yakın kızıl ötesi spektrum tekniğinin (NIRS) ortaya çıkmasıyla beraber ilaç sanayinden, gıda sektörüne, adli ve güvenlik bilimlerinden yer gözlem ve uzaktan algilama bilimine kadar birçok alanda yer bulmuştur (Pasquini, 2003). Uygulama alanlardan birisi de tarımsal üretimler ve araştırmalarıdır. NIRS teknolojisinin günümüzde ulaştığı noktaya gelmesine olanak sağlayan araştırmalar çoğunlukla tarım ile ilgili alanlarda yapılmıştır. Yakın-Kızılötesi Spektrumu 1960'lı y1llarda Amerika Tarım Bakanlığında görev alan Carl Norris tarafindan geliştirilmiş olan bir tekniktir (Norris, 1988). Carl Norris; NIRS ile yaptığı ilk çalışmada tarımsal ürünlerdeki nem miktarını ölçmek için yeni bir metot geliştirmeyi amaçlamıştır (Günal, 2007; Pasquini, 2003). Spektrumun; görünür, orta ve yakın kızılötesi kısımlarında çeşitli dalga boyu aralıklarındaki 1şınımları, toprağın 
molekül, atom veya iyonlarının farklı enerji seviyelerine geçişleri sırasındaki davranışlarını belirlemeyi amaçladıkları bilinmektedir. $\mathrm{Bu}$ nedenle spektroskopi kavramı ortaya atılmıştır. Spektroskopi; “ bir örnekteki atom, molekül veya iyonların, bir enerji düzeyinden diğerine geçişleri sırasında absorblanan veya yayılan elektromanyetik 1şımanın ölçülmesi ve yorumlanmasıdır (Kılıç vd., 1998). Toprak yüzeyine gönderilen elektromanyetikspektrumun kızılötesi bölgesinde bulunan radyasyonların, her bir toprak özelliğine ait spektrum aralığında etkili olması, toprakların bileşimleri hakkında daha doğru sonuçlar elde edilebilmesine olanak sağlayabilir.

Mouzen vd. (2005), NIRS spektroskopi kullanarak Belçika ve Fransa'nın kuzeyinde bulunanbirçokarazidenalınantoprakörnekleriyle tekstür sınıflarını belirlemeyi amaçlamışlardır. Toplam 365 toprak örneği kaba kum, ince kum, tınlı ve killi olmak üzere dört tekstür sınıfına ayrılarak sınıflandırılmıştır. Kalibrasyon ve doğrulama setinde örnekler için sınıflandırma doğruluğu sirasıyla \% 85.7 ve \% 81.8 olarak gözlemlenmiştir. Dematte (2002), toprakların yansıma enerjilerinin, onları karakterize etmek ve ayırmak için kullanılıp kullanılamayacağını belirlemek amacıyla yapılan çalışmada, Sao Paulo, Brezilya'da bulunan Bauru bölgesinde 6 farklı sınıftan toprak örnekleri kullanılmıştır. Topraklardan yansıma değerlerinin iyi bir şekilde ayırt edilebilmesi için oluşturulan bir yöntemin kullanıldığı araştırmada 2 sınıf dışında diğer tüm sınıfların yansıma verileri ile karakterize edilerek ayırt edilebildiği belirlenmiştir. Bilgili vd. (2010), Türkiye'nin kuzeyinde 32 ha' lık bir alan üzerinde grid sistemi kullanarak 512 farklı bölgeden alınan toprak örnekleri ile yaptıkları çalışmada, Entisol toprak ordosu içerisinde sınıflandırılan 4 farklı toprak serisinin görünür-yakın kızılötesi spektroskopisi (VNIR) yardımıyla çeşitli toprak özelliklerini hesaplamışlardır. PLSR ve Multivariate Adaptive Regression Splines (MARS) metotlarının kullanıldığı çalışmada, Ca ve $\mathrm{Mg}, \mathrm{Kdk}$, organik madde, kil, kum ve kireç içerikleri gibi bazı toprak özellikleri açısından güçlü korelasyonlar elde etmişlerdir.

VNIRS ile Çukurova Bölgesi'nde tanımlanan serilerin yansıma karakteristikleri göz önünde bulundurularak; organik madde (om), kum, silt, kil ve kireç içeriklerinin, seri düzeyinde ayırt edilebilmesinde alternatif ve kollektif bir ölçüm yöntemi olabileceği düşünülmektedir. Bu sayede, arazi çalışmaları sırasında morfolojik gözlemlere dayanan, zaman alıcı, yorucu ve yüksek maliyetli işlemlerin aksine daha hızlı, çabuk, arazide harcanacak süreyi en aza indirgeyen, daha güvenilir ve doğru sonuçlar verebilen bir yöntem bulunması hedeflenmektedir.

\section{MATERYAL ve METOD}

\section{Çalışma Alanının ve Tanımlanan Toprak Serilerinin Genel Özellikleri}

Çalışma alanının; doğusunda Ceyhan Nehri (360 51'31'K; 350 51' 44” D) , kuzeyinde MersinAdana-Ceyhan otoyolu (360 57'17' K; 350 19'20" D) batısında Mersin il merkezi sınırı (36049'35" K; 340 42' 16" D) ve güneyinde Akdeniz kıyıları (360 32' 20” K; 350 20' 21"

D) bulunmaktadır (Şekil 1). Çalışma alanını 


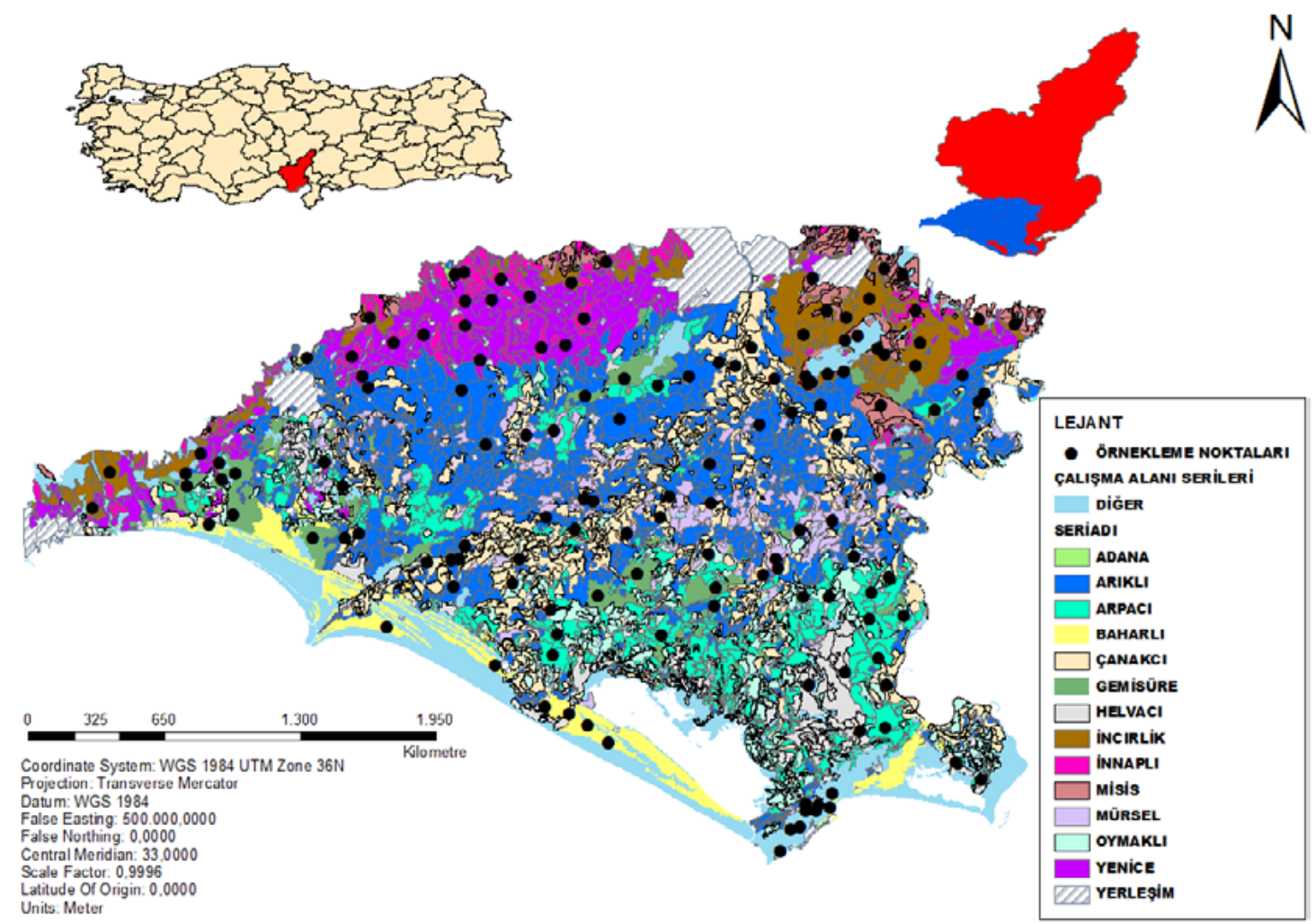

Şekil 1.Çalışma alanı coğrafi konumu ve örnekleme noktaları (Türkiye haritası (sol üst)- Adana ili ve Çukurova bölgesi haritası (să̆ üst)Çalışma alanının toprak serileri haritası (alt))

oluşturan Çukurova Bölgesi, Dinç vd. (1995) tarafindan fizyoğrafik ve jeolojik olarak oldukça değişken ve karmaşık bir yapıda olması nedeniyle iki ana bölgeye ayrılmıştır. Kireçtaşları, konglomera, marn ve benzeri materyallerin oluşturduğu ova içerisindeki yüksek araziler birinci grup olarak tanımlanırken, ikinci grup; zaman faktörüne bağlı olarak depolanmış aluviyal materyalleri içerisine almaktadır. Toprak haritasının üretilmesi sırasında ova, jeomorfolojik özelliklerine bağlı olarak 7 fizyoğrafik üniteye ayrılmıştır. Bu fizyoğrafik üniteler içerisinde tanımlanmış 20 farklı toprak serisi bulunmaktadır. Bu seriler arasında ovanın değişik alanlarında yayılım gösteren 6 farklı fizyoğrafik ünite üzerinde 13 farklı toprak serisi ve bunların önemli fazlarını temsil edecek şekilde örnekleme noktaları belirlenmiştir. $\mathrm{Bu}$ seriler;
İnnaplı ve Adana (Yüksek fluvo-deniz terasları); İncirlik, Yenice, Misis (Bajada topraklar); Çanakçı ve Oymaklı (Genç nehir terasları); Arıklı, Arpacı, Mürsel (Yaşlı nehir terasları); Helvacı ve Gemisüre (Yaşlı nehir terasları) ve Baharlı (Kıyı kumulları üzerinde oluşanlar) dır.

\section{MATERYAL}

Çalışmada, Dinç vd. (1995) tarafindan yazılan "Çukurova Bölgesi Toprakları" kitabı materyal olarak kullanılmıştır. ArcGIS 10.4.1 paket programı sayesinde, üretilen detaylı toprak haritasına ait sayısallaştırılmış veriler kullanılmıştır. Çalışma alanı içerisinde 126 farklı haritalama birimi örneklenmiştir. Örneklemeler horizon esasına dayalı olarak 
yapılmış ve seri farklılıkları gözetilerek farklı haritalama birimleri içerisinden her bir seriye ait farklı horizon derinlikleri, standartlaştırılmış derinlikler olarak;0-30, 30-60, 60-90, 90-120 $\mathrm{cm}$ derinliklerine göre düzenlenmiş ve 531 adet bozulmuş toprak örneği toprakçı burgusu yardımıyla alınmıştır. Örnekleme noktaları seçilirken fizyoğrafik birimlerine ve renk başta olmak üzere, birbirinden farklı özellikler göstermesine bağlı olarak seçilen seriler örneklemeye dahil edilmiştir. Ayrıca, yüzey ve yüzey altı örnek sayıları da belirtilmiştir (Çizelge 1). Söz konusu örneklerde serilerin yansıma değerlerini belirlemek için 350-2500 $\mathrm{nm}$ dalgaboyları aralığında topraktan yansıma değerlerini ölçebilen görünür-yakın kızılötesi spektroskopisi (VNIRS) kullanılmıştır. NIRS okumaları sonucu elde edilen ham veriler UnscramblerX V.10.5 (CAMO Inc.,1998) istatistiki paket programı kullanılarak anlamlı hale getirilmiştir. Ayrıca yansıma değerleriyle ölçülen toprak özellikleri arasındaki korelasyonun sağlanması amaciyla; organik madde, tekstür, kireç analizleri yapılmıştır. Laboratuvar ve yansıma analizleri için ayrılan örnekler açık havada kurutulup, öğütüldükten sonra 2 milimetrelik (mm) elekler kullanılarak analize hazır hale getirilmiştir.

Fizyoğrafik birimleri bakımından yüksek fluvo deniz terasları üzerinde bulunan İnnaplı ve Adana serileri yüzey ve yüzey altında koyu olmayan açık kırmızımsı-kahverengimsi (5YR 3/4) bir renge sahiptir ve orta-yüksek derecede kireç birikiminin görüldüğü, tüm profilleri ince tekstürlü toprakları içerir. İncirlik, Yenice ve Misis serilerinin fizyografik birimleri bajada toprakların oluşturduğu, yüzeyde kırmızımsı kahve ve yüzey altında koyu kahverenge sahip (7.5YR 3/3 veya 10 YR 4/3) düşük seviyelerde

Çizelge 1. Fizyoğrafik birimlerine ve renk özelliklerine göre seçilen seriler

\begin{tabular}{|c|c|c|c|c|c|}
\hline Fizyografik Ünite & Seriler & Renk & Yüzey* & Yüzeyaltı* & $\begin{array}{r}\text { Toplam Alan } \\
\text { (ha) }\end{array}$ \\
\hline \multirow{2}{*}{ Yüksek Fluvo-Deniz Terasları } & İnnapli & $5 Y R 3 / 4$ & 18 & 27 & $6.498,27$ \\
\hline & Adana & $5 Y R 3 / 3$ & 6 & 9 & 191,26 \\
\hline \multirow{3}{*}{ Bajada Topraklar } & İncirlik & 10YR 4/4 & 18 & 9 & $10.256,89$ \\
\hline & Yenice & $10 \mathrm{YR} 4 / 3$ & 30 & 15 & $16.397,98$ \\
\hline & Misis & $7.5 \mathrm{YR} 3 / 3$ & 18 & 27 & $6.045,48$ \\
\hline \multirow{2}{*}{ Genç Nehir Terasları } & Çanakçı & $2.5 Y 5 / 3$ & 36 & 36 & $26.163,62$ \\
\hline & Oymaklı & $2.5 Y 5 / 2$ & 18 & 18 & $12.165,49$ \\
\hline \multirow{3}{*}{ Yaşlı Nehir Terasları } & Arıklı & $2.5 \mathrm{Y} 4 / 4$ & 36 & 36 & $46.326,18$ \\
\hline & Arpac1 & $10 \mathrm{YR} 3 / 2$ & 18 & 27 & $19.591,26$ \\
\hline & Mürsel & $10 Y R 3 / 3$ & 18 & 27 & $8.866,26$ \\
\hline \multirow{2}{*}{ Delta Tabanı Toprakları } & Helvaci & $2.5 \mathrm{Y} 6 / 2$ & 12 & 18 & $8.448,86$ \\
\hline & Gemisüre & $10 \mathrm{YR} 4 / 2$ & 18 & 18 & $6.955,00$ \\
\hline Kıyı Kumulları & Baharlı & $2.5 \mathrm{Y} 5 / 1$ & 6 & 12 & $7.758,82$ \\
\hline Tüm Serilerin Toplam Alanı & & & 252 & 279 & $175.665,37$ \\
\hline
\end{tabular}

(*):Örnek Sayıs1 
kireç içerikli, ince tekstürlü topraklardır. Genç nehir terasları üzerinde bulunan genç oluşumlu Çanakçı ve Oymaklı serileri zeytuni-kahverenge sahip (2.5Y 5/3 veya 5/2) ,yüksek kireç içerikli ve orta tekstürlü topraklardır. Yaşlı nehir terasları üzerinde yer alan Arıklı, Arpacı ve Mürsel serileri kireç içerikleri bakımından çok yüksek değerlere sahiptir. Çok ince tekstürlü olan bu topraklar koyu grimsi kahverenge (2.5Y 4/4) sahiptir. Helvacı ve Gemisüre serileri delta tabanlı topraklar üzerinde oluşan ve taban suyu bakımından oldukça ve ağır bünyeli topraklardır. Koyu grimsi kahverenge sahip (10YR 4/2 veya $2.5 Y$ 6/2) ve kireç içerikleri çok yüksektir. Kıyı kumulları üzerinde oluşan Baharlı serisi ise yüksek kum içeriğine sahip düşük kireç içeren, açık renkli topraklardır.

\section{METOD}

Çalışmada Dinç vd. (1995) tarafindan Çukurova Bölgesi'nde yapılan etüt ve haritalama çalışmalarının bir çıktısı olan seri bazında toprak haritaları kullanılarak, bölgede yaygın dağılım gösteren toprak serileri seçilmiştir. Mevcut haritadaki seri özellikleri ve sinırlarından faydalanılarak toprak örneklemesi yapılmıştır. Örnekleme her bir horizonun farklı derinliğe ve farklı toprak özelliğine sahip olduğu göz önünde bulundurularak horizon esasına göre yapılmıştır. Haritalandırılan seri özelliklerine bağlı olarak örnekleme amacina uygun belirlenen serilerin farklı lokasyonlarında bulunan haritalama birimleri seçilerek örneklenmiştir. 13 farklı toprak serisi ve bunların önemli fazlarını temsil edebilen ve ovanın değişik alanlarında yayılım gösteren örnekleme noktaları belirlenmiştir.
Örnekleme, I. ve II. arazi çalışmaları Dinç vd. (1995) tarafindan yapılmış ve kesin sınırları çizilmiş toprak serilerini gösteren seri haritasından, yaygın serilerin ayırt edilmesi ve seri düzeyinde farklılıkları saptamak için kullanılmıştır. $\mathrm{Bu}$ sayede, , yansıma tekniğinin toprak özelliklerinin ayırt edilmesi ve serilerin haritalaması üzerine kabiliyetinin test edilmesi amaçlanmıştır. Çalışmanın amacına uygun olarak hazırlanan ve örnekleme ve analiz aşamalarında

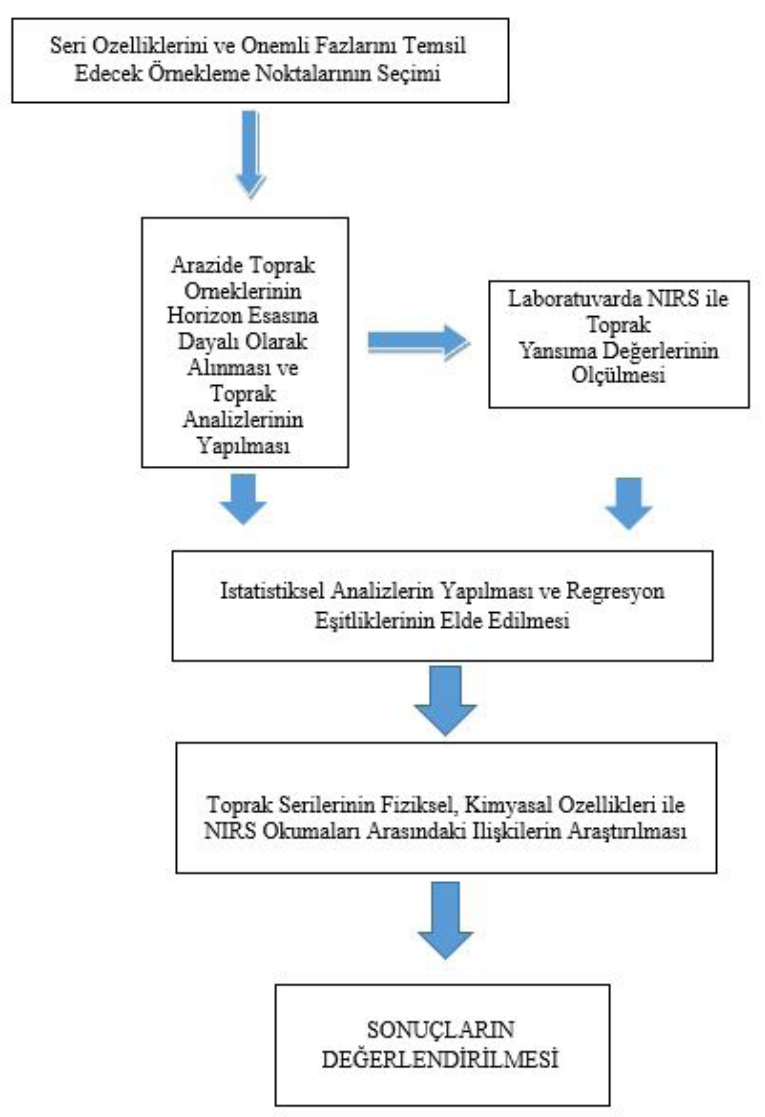

Şekil 2. Çalışma sırasında uygulanan yöntemlerin akış şeması 
izlenilen adımları gösteren bir akış diyagramı oluşturulmuştur (Şekil 2).

\section{VNIRS ile Yansıma Değerlerinin Elde Edilmesi ve İşlenmesi}

Horizon esasına göre alınan toprak örnekleri, görünür-yakın kızılötesi spektroskopisi (VNIRS) Analytical Spectral Devices (ASD) FieldSpec $囚 3$ aletiyle okunmuştur (PANalytical, B.V, Boulder, Colorado, USA, Analytical Spectral Devices). ASD FieldSpec $₫ 3$ spektroskopisi; yansıma değerlerinin ölçülmesi ve topraktan geri yansıyan görünür ve yakın kızılötesi 1şınları toplayan ana güç kaynağı, 1şının doğru açıyla toprağa iletilmesini ve örnekten saçılan 1şınların yeniden güç kaynağına taşınmasını sağlayan probe, 1şı̆̆ın kırılmasını önlemek amaciyla probe'un ucuna takılan ve toprak numuneleri için özelleştirilmiş kuvars içerikli camdan yapılmış filament lamba, aletin yansıma değerlerinin düzgün okunması ve kırılmaların en aza indirgenmesi amacıyla gönderilen ışının kalibrasyonunda kullanılan dairesel beyaz referans Spectralon panel (Labsphere Inc., North Sutton, NH, USA) ve okunan yansima değerlerinin işlenmesi ve depolanmasını sağlayan bir dizüstü bilgisayardan oluşmaktadır. Örneklerin yansıma değerleri okunmadan önce beyaz referans (WR: white reference) okutularak cihazın kalibrasyonu sağlanmıştır. Her bir numune yaklaşık 20-30 gr tartılarak beyaz renkli okuma kapları içerisine konulmuş, toprak yüzeyinden alınan yansımaların sağlıklı bir şekilde elde edilebilmesi için plastik bir aparat yardımıyla yüzeyleri bastırılarak homojenize edilmiştir. Alet okuması esnasında gönderilen ıșınların kırılmasının en aza indirgenmesi amaciyla probe toprak yüzeyine tam olarak temas ettirilmiştir. Yansımalardan kaynaklanan hata oranını azaltmak amaciyla probe örnekleme yüzeyinin 3 farklı noktasına uygulanmıştır. Her bir örnek için elde edilen toplam 30 farklı yansıma verisinin ortalaması alınarak bilgisayara kaydedilmiştir. Her 20 dakikada bir WR alınarak cihazın kalibrasyonu güncel tutulmuştur. Alet okumasından elde edilen ham yansıma değerleri “ASCII” formatına dönüștürüldükten sonra yansıma grafikleri ve istatistiki verileri elde edilmiştir. Yansıma değerleri istatistiki olarak en küçük kısmi kareler regresyon (EKKR) yöntemi kullanılarak elde edilmiştir. İstatistiki değerler ile toprak serilerine ait fiziksel ve kimyasal özellikler arasındaki ilişki belirlenerek sonuçlar değerlendirilmiştir.

\section{BULGULAR ve TARTIŞMA}

Toprakların fiziksel ve kimyasal özelliklerinin tahmin edilmesinde VNIR spektrometresinin kullanımı giderek artmaktadır. Bu çalışmada toprak serilerinin özelliklerini dikkate alarak VNIR spektroskopisi ile ayırt edilebilirliği araştırılmıştır. Çalışma alanından ilk olarak, 141 farklı noktadan horizon esasına göre örneklenen 252 yüzey ve 279 yüzey altı örneği toplanmıştır (Çizelge 1). Ancak, bazı yüzey örneklerinin (51 adet) serilerin derinlik özelliklerine bağlı olarak, 350- $2500 \mathrm{~nm}$ dalga boyu aralıklarında yüzeyaltı örneklemesi gibi kabul edilmesinin, yansıma sonuçları analizlerinin güvenilirliği bakımından daha yüksek korelasyon sonuçları verebileceği tespit edilmiştir. Bu nedenle, 201 yüzey ve 330 yüzey altı toprak örneğinin yansıma sonuçları 
elde edilmiştir (Çizelge 2). Birbirinden farklı fizyoğrafik birimlerde yer alan ve fiziksel, kimyasal ve morfolojik özellikleri yönünden farklılıklara sahip serilerin yansıma değerleri incelenmiştir. Yansıma değerleri istatistiksel olarak değerlendirilip yorumlanmıştır. Yüzey ve yüzey altı toprak örneklerinin yansıma grafikler ayrıca üretilip yorumlanmıștır.

\section{Toprak Serileri ve Görünür-Yakın Kızılötesi} Yansıma Değerlerinin İstatistiksel Analizleri

Toprak serilerinin yansıma değerleri ve organik madde, kum, silt, kil ve kireç içeriklerinin

Çizelge 2. Toprak örneklerinin yansıma değerleri ve toprak özellikleri (organik madde, kum, silt, kil ve kireç) arasındaki istatistikler (çapraz doğrulama yöntemine göre)

\begin{tabular}{|c|c|c|c|c|c|c|c|}
\hline \multirow{2}{*}{$\begin{array}{l}\text { Tüm Veri Seti } \\
(n=531)\end{array}$} & \multicolumn{3}{|c|}{ Kalibrasyon(CV) } & \multicolumn{4}{|c|}{ Validasyon(CV) } \\
\hline & $\mathbf{R 2}$ & RMSE & SEC & & $\mathbf{R 2}$ & RMSE & SEC \\
\hline Kil & 0,47 & 11,50 & 11,60 & 0,44 & & 11,96 & 11,97 \\
\hline Silt & 0,44 & 10,09 & 10,10 & & 0,41 & 10,36 & 10,37 \\
\hline Kum & 0,36 & 14,73 & 14,75 & & 0,29 & 15,33 & 15,37 \\
\hline Om & 0,32 & 0,33 & 0,33 & 0,26 & & 0,34 & 0,34 \\
\hline $\mathrm{CaCO}_{3}$ & 0,21 & 6,21 & 6,22 & 0,18 & & 6,30 & 6,31 \\
\hline \multirow{2}{*}{$\begin{array}{l}\text { Yüzey Veri Seti } \\
(n=201)\end{array}$} & \multicolumn{3}{|c|}{ Kalibrasyon(CV) } & \multicolumn{4}{|c|}{ Validasyon(CV) } \\
\hline & $\mathbf{R 2}$ & RMSE & SEC & & $\mathbf{R 2}$ & RMSE & SEC \\
\hline
\end{tabular}

\begin{tabular}{lccccccc}
\hline Kil & 0,55 & 9,58 & 9,60 & 0,46 & & 10,59 & 10,61 \\
Silt & 0,52 & 9,38 & 9,40 & 0,43 & 10,20 & 10,23 \\
Kum & 0,22 & 11,51 & 11,54 & 0,10 & 12,55 & 12,48 \\
Om & 0,10 & 0,31 & 0,33 & 0,07 & 0,32 & 0,32 \\
$\mathrm{CaCO}_{3}$ & 0,56 & 6,22 & 6,22 & 0,51 & 4,73 & 4,75 \\
\hline
\end{tabular}

( $\mathrm{R}^{2}$ :determinasyon katsayısı; RMSE: ortalama karekök standart hata; SECV; standart hata; CV: çapraz doğrulama; PLSR: En küçük kısmi kareler regresyonu) 
tanımlayıcı istatistikleri Çizelge 2'de verilmektedir. Çizelge 2, uygulanan tüm ve yüzey veri setinin; $\mathrm{R}^{2}$, ortalama karekök standart hata (RMSE) ve tahmin standart hata (SEP), kalibrasyon standart hata (SEC) değerlerini göstermektedir.

Tüm veri setini içine alan 531 toprak numunesi ile 201 yüzey ve yüzey altı toprak numunesinin istatistiksel analizleri yapılmıştır. Yansıma değerleri ve toprak özellikleri arasındaki regresyon değerleri, EKKR istatistiksel analiz metodu kullanılarak elde edilmiştir. EKKR yöntemi, bir çok araştırmada kullanılmış ve diğer istatistiki yöntemlere göre daha güvenilir ve doğru sonuçlar verdiği farklı araştırmacılar tarafından belirtilmiştir (Chang vd., 2002; Böğrekci ve Lee, 2006; Mouazen vd., 2006). Kalibrasyon ve tahmin için ayrılan toprak örneklerine çapraz doğrulama (cross validation) işlemi uygulanmıştır. Çapraz doğrulama işlemi, "bir makine öğrenmesi modelinde yapılan test hatasını daha iyi tahmin edebilmek için model seçiminde kullanılan bir tekniktir. Çapraz doğrulamanın ardındaki temel prensip, eğitim veri setinden doğrulama kümeleri olarak bilinen örnek gözlem bölümlerini oluşturmaktır" (Anonim, 2018). Bu sayede kalibrasyon modelinin ortaya çıkması beklenmektedir.

Çapraz doğrulama sonucu kil için tüm veri setindeki toprak örneklerinin yansıma değerleri ile kalibrasyon arasındaki $\mathrm{R}^{2}$ değerleri; kil için 0,47 ; silt için 0,44 ; kum için 0,36 ; organik madde (o.m) için 0,32; kireç $\left(\mathrm{CaCO}_{3}\right)$ için 0,21 bulunmuştur. Kalibrasyonun RMSE değerleri oldukça yüksektir ve sırasıyla; kil, 11.58; silt, 10.09; kum, 14.73; om, 0.33; kireç, 6.21 olarak bulunmuştur. Ayrıca SEC, kalibrasyonun RMSE değerine çok yakındır. Benzer durum validasyon seti içinde görülmektedir. Validasyon setinde sırasıyla; kil için, $\mathrm{R}^{2}$ 0.44; RMSE 11.96; SEC 11,97 ; silt için R R $^{2}$ 0.41, RMSE 10.36, SEC 10.37; kum için $\mathrm{R}^{2}$ 0.29, RMSE 15.33, SEC 15.37, om için $\mathrm{R}^{2}$ 0.26, RMSE 0.34, SEC 0.34, kireç için, R ${ }^{2}$ 0.18, RMSE 6.3, SEC 6.31 olarak bulunmuştur. Tüm veri setinin daha doğru sonuçlarla tahmin edilebilmesi için mevcut veri setinden 350 örnek kalibrasyon, geriye kalan 181 örnek ise tahmin (prediction) için kullanılmıştır (Çizelge 3).

Modelin kalibrasyonu için kullanılan veri setinin $\mathrm{R}^{2}$ değerleri sırasıyla; kil 0.48 ; silt 0.49 ; kum 0.33; om 0.34 ve kireç 0.35 dir. Modelin kalibrasyonun RMSE ve SEC değerleri çapraz doğrulama sonucu elde edilen hata değerlerine benzer olup, yüksek olduğu görülmektedir. Tahmin modelinin validasyon setinde ise durum çapraz doğrulama sonucu elde edilen $\mathrm{R}^{2}$ değerlerine benzerdir. Sirasıyla $\mathrm{R}^{2}$ değerleri; kil 0.45 ; silt 0.45 ; kum 0.28 ; o.m 0.26 ve kireç 0.28 olarak bulunmuştur. RMSE ve SEC değerleri tıpkı çapraz doğrulamada olduğu gibi birbirine yakın ve küçük nüanslar dışında birbirine benzerdir. Benzer şekilde 201 yüzey-yüzey altı örneği için de veri seti model oluşturmak amacıyla ikiye bölünmüştür (Çizelge 3). Toprak örneklerinin 140 tanesi modelin kalibrasyon seti için, geriye kalan 61 tanesi ise tahmin amaciyla kullanılmıştır. Kalibrasyon için kullanılan 140 yüzey-yüzey altı örneğinin $\mathrm{R}^{2}$ değerleri; kil 0.55 ; silt 0.52 ; kum 0.22 ; o.m 0.18 ve kireç 0.64 dür. Validasyon setinde ise $\mathrm{R}^{2}$; kil 0.46 , silt 0.43 , kum 0.10 , o.m 0.14 ve kireç 0.56 olarak bulunmuştur. Her iki tahmin modeli arasında dikkate değer bir 
Çizelge 3. Toprak örneklerinin yansıma değerleri ve toprak özellikleri(organik madde, kum, silt, kil ve kireç) arasındaki istatistikler (tahmin yöntemine göre)

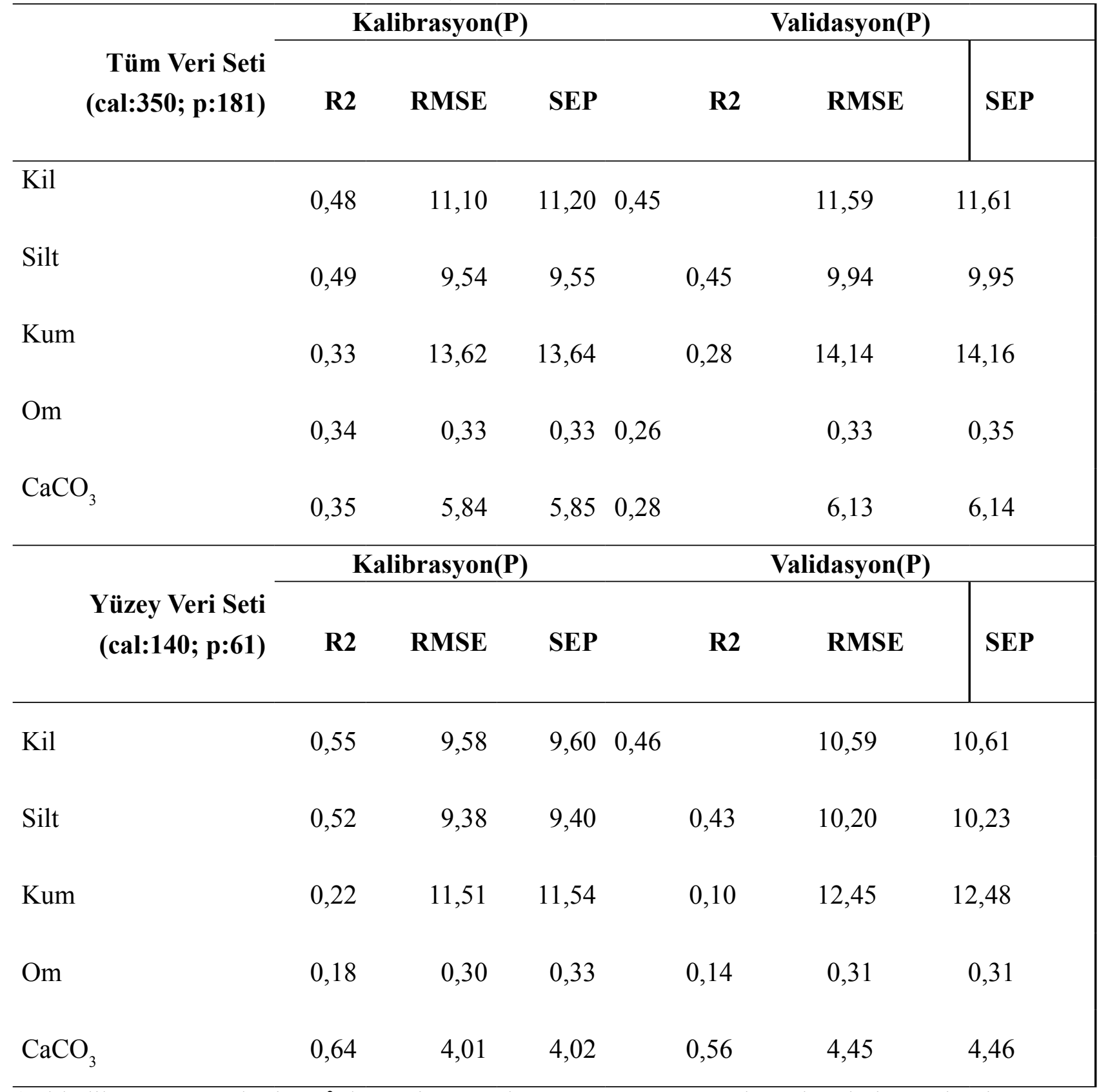

(cal:kalibrasyon; p:tahmin; R²:determinasyon katsayıs1; RMSE: ortalama karekök standart hata; SEP; tahminin standart hatası; PLSR: En küçük kısmi kareler regresyonu)

farklılık görülmemesine rağmen, tüm ve yüzey veri setleri içindeki örneklerin bir kısmının kalibrasyona ayırılarak değerlendirilen tahmin modellemesinin, diğerine göre biraz daha yüksek $\mathrm{R}^{2}$ ve daha düşük RMSE değerlerine sahip olduğu gözlemlenmektedir. Ancak hem veri setinin ayırt edilerek hem de birebir (çapraz) doğrulama yöntemi kullanılarak yapılan her iki tahmin içinde elde edilen $\mathrm{R}^{2}$ değerleri yetersiz kalmıştır. Yukarıda özellikleri verilen (Çizelge 
1) ve yansıma değerleri araştırılan toprak serilerinin neredeyse tamamında kireç içerikleri çok yüksektir. $\mathrm{Bu}$ nedenle, yansıma ile ilişkisi bulunan toprak özelliklerinin belirlenmesi aşamasında toprakta bulunan yüksek kireç içeriği, diğer toprak özelliklerini maskeleyerek yansıma değerlerinin $\mathrm{R}^{2}$ değerlerinin düşük bulunmasına neden olmuştur. Ayrıca, açık bir renge sahip olan İnnaplı ve Adana serileri, daha koyu renkteki Arıklı, Arpacı ve Mürsel serilerinden daha yüksek yansıma değerlerine sahiptir. Bunun yanı sıra, diğer serilerden tanecik boyutu yönünden farklı olan (kum içeriği yüksek) Baharlı serisi topraklarının yansıma değerleri de özellikle yüzey toprağının $\mathrm{R}^{2}$ değerlerini, diğer serilere oranla daha olumlu yönde etkilemiştir.

Her iki veri seti incelendiğinde beş farklı toprak özelliği (kil, silt, kum, om, kireç) model içerisinde ilişki aranan yansıma değerleri ile iyi bir kalibrasyon gösterememiştir. Daha önce yapılmış ve yukarıda verilen sonuçlarla benzerlik gösteren birkaç çalışmada, kum, silt, kil için doğrulama sonuçları sırasıyla; $\mathrm{R}^{2} \quad 0.56$, RMSE 10.3 (Ben-Dor ve Banin, 1995); R² 0.60, RMSE 1.9 (Rossel vd., 2006); $\mathrm{R}^{2}$ 0.53, RMSE 14.5 (Islam ve ark., 2003); $\mathrm{R}^{2}$ 0.36, RMSE 13.2 (Malley vd., 2000), R² 0.57, RMSE 17.6 (Brown ve ark., 2006) bulunmuştur. Stenberg vd. (2010) düşük $\mathrm{R}^{2}$ değerleri ve kısmen yüksek RMSE değerlerinin, her bir alt veri seti içinde k1sıtlı jeolojik heterojenliğin tahmin sonuçları üzerinde önemli bir etkiye sahip olduğunu ileri sürmüşlerdir. Çalışma alanı içerisinde yer alan toprakların jeolojik bakımdan homojen bir yapıda olduğu bilinmektedir. Çalışma alanın büyük bir kısmı ayrışmamış kuvartener yapıda bulunmaktadır. Ayrıca; söz konusu alan Seyhan ve Ceyhan Nehirlerinin etkisiyle taşınan alüviyallerin birikmesi sonucu oluşmuş ve ova niteliği kazanmıştır (Özbek vd.,1974).

Topraklar arasında fiziksel, kimyasal özellikler yönünden farklılıklar olmasına rağmen, toprakların alüviyal kökenli oluşu yansımayı ve yansımaların değer aralığını etkileyen önemli bir etken olabilir. Bu durum yansıma istatistiklerinin düşük bulunmasının nedenlerinden birisi olabilir. Bununla birlikte toprakların yüksek kireç içeriği albedo (toprak yüzeyine gönderilen 1şınların farklı yönlerde saçılarak yansımayı arttırması) etkisini arttıracağından özellikle toprağın tekstürel bileşimini oluşturan kum, silt, kil başta olmak üzere om'nin de maskelenmesine neden olmuştur. Çalışmanın amacına bağlı olarak, yansıma değerleri okunan toprakların ilgili beş özelliği (kum, silt, kil, om, kireç) için analizler tekrarlanmamış olup mevcut verilerin doğruluğu kabul edilerek benzer seri ve haritalama birimlerinin daha önceden yapılmış referans analizleri baz alınarak hesaplanmıştır. Ancak, referans alınan değerler ile mevcut topraklara ait yansıma derinlikleri arasında önemli bir korelasyon bulunamamıştır.

\section{Toprak Serilerinin Görünür-Yakın Kızılötesi Yansıma Değerleri ile Belirlenebilmesi}

Toplam 531 toprak numunesi, $350 \mathrm{~nm}$ ile $2500 \mathrm{~nm}$ arasında VNIR spektralardan elde edilen yansıma değerleriyle pürüzsüzleştirme, sinyal ve parazit oranının düzenlenmesi, türev alma gibi herhangi bir ön işleme tabi tutulmadan doğrudan saçılma grafiğine yerleştirilerek yansıma grafiğinin göz 
vasıtasıyla yorumlanması amaçlanmıştır. VNIRS ile okunan 531 toprağın yansıma grafiği Şekil 3 'te verilmiştir. Yansıma grafiği incelendiğinde, yansıma değerlerinin başarılı dağılım gösterdiği görülmektedir. $\mathrm{Bu}$ duruma, daha fazla sayıda ve daha çok alansal çeşitliliğe sahip toprak örneklerinin, yansıma grafikleri üzerinde daha başarılı dağılım göstereceği ve bunun da spektral tahmin kalitesine olumlu şekilde etki edebileceği düşünülmektedir (Mouzen ve Kuang., 2011). Ancak, yansıma değerlerinin istatistiksel sonuçlarına etki eden ve düşük $\mathrm{R}^{2}$ değerlerinin bulunmasına neden olan dar yansıma aralığı, saçılım grafiğinde de göze çarpmaktadır. Şekil 3 'te, toprak örneklerinin yansıma eğrilerinin 0.2 - 0.5 aralığında yoğunlaştığ 1 görülmektedir. Bir diğer önemli husus, yaklaşık olarak 1420 ve 1900 nm'ler arasında iç bükey şekilde görülen yansıma farklılıklarıdır. İlgili dalga boylarında (1420 nm ve $1900 \mathrm{~nm}$ ) OH moleküllerinin titreşimlerinin simetrik ve asimetrik esneme ve bükülme hareketleri (Hunt,1977) ve toprakta bulunan mevcut suyun yüksek tonları ve esasları neden olmuştur (Chang ve Laird, 2002).

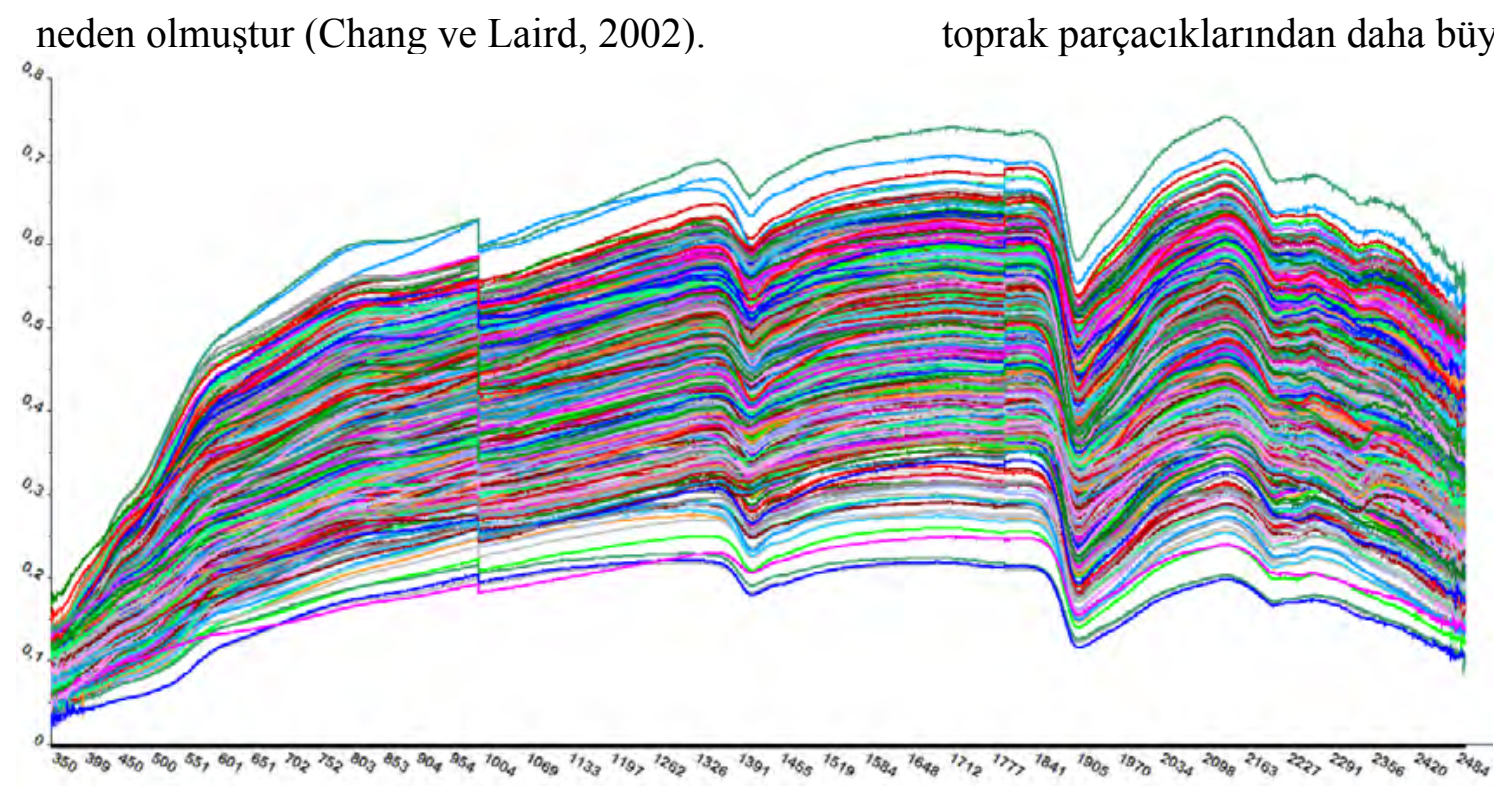

Şekil 3. Tüm veri setinin (531) yansıma grafiği
Toprak yüzey alanının artması toprağın tekstürünün incelmesine ve toprak tanecikleri etrafinda ince bir tabaka şeklinde bulunan higroskopik nem yoğunluğunun daha fazla artmasına neden olacaktır. Şekil 4 yüzey (0-30, $30-60 \mathrm{~cm})$ ve yüzey-altı $(30-60,60-60,90-120$ $\mathrm{cm})$ toprak yansımalarının saçılım grafiğini göstermektedir. Yansıma grafiği 350 ile 2473 $\mathrm{nm}$ dalgaboyu aralığında başarılı bir spektral dağılım göstermiştir. Şekil 3 'te tüm veri setinin yansıma grafiğinde olduğu gibi şekil 4'te de yansımaların değer aralıklarının dar bir aralıkta olduğu gözlemlenmektedir.

Bu durum tüm veri setinde olduğu gibi yüzey ve yüzey-altı veri setinde de $\mathrm{R}^{2}$ değerlerinin düşük RMSE değerlerinin yüksek bulunmasına neden olmuştur. Yaklaşık 1400 nm'de toprakların yansımasında belirgin bir azalış gözlemlenmektedir. $\mathrm{Su}$, mineral yüzeylerinde ince bir tabaka şeklinde adsorbe edilir ve serbest akışkan su, albedo’yu azaltan genel etkilere sahip por boşluklarını doldurur. Çoğunlukla bu etki, toprak parçacıklarından daha büyük ve onlara 


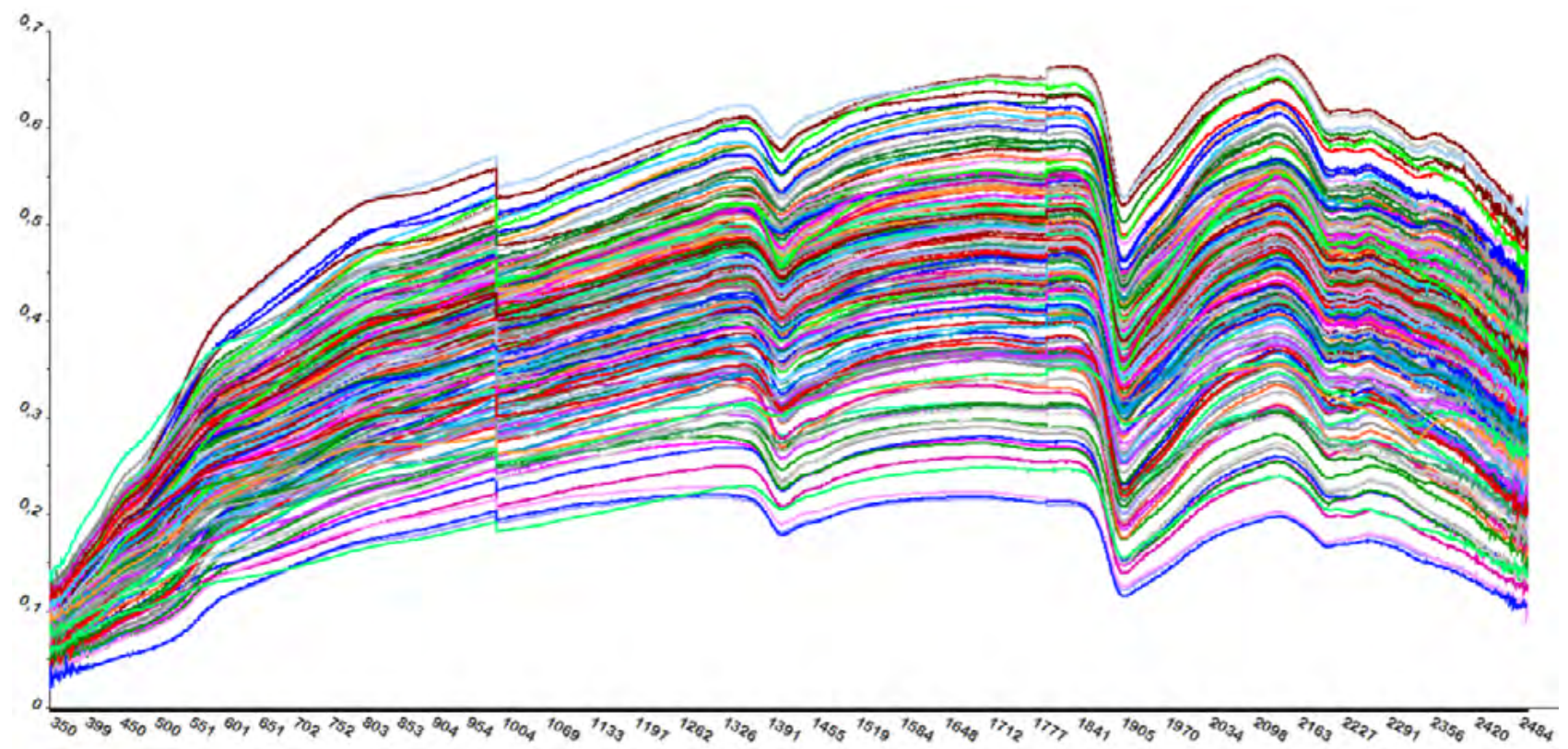

Şekil 4. Yüzey $(0-30 \mathrm{~cm})$ ve yüzey altı $(30-60 ; 60-90 ; 90-120 \mathrm{~cm})$ yansıma grafiği

daha yakın olan toprak havası ve suyundan, toprak parçacıklarını çevreleyen ortamının gerçek kırılma indekslerindeki değişimine katkı sağlar (Whalley ve ark., 1991). Benzer durum yaklaşık $1900 \mathrm{~nm}$ dalga boyundaki azalış içinde geçerlidir.

\section{SONUÇ ve ÖNERİLER}

Toprak örneklerinin birbirinden farklı yansıma değerlerieldeedilmiştir. Dinçvd(1995)tarafından ölçülen organik madde, tekstür ve kireç içerikleri ile kalibre edilen yansıma değerleri için sonuçlar şu şekilde oluşmuştur: çapraz doğrulama sonucu kil için tüm veri setindeki 531 toprak örneğinin yansıma değerleri ile kalibrasyon arasındaki $\mathrm{R}^{2}$ değerleri; kil için, 0,47; silt için, 0,44; kum için, 0,36; organik madde için, 0,32; kireç için, 0,21 bulunmuştur. Benzer durum validasyon seti içinde görülmektedir. Validasyon setinde sirasıyla; kil için, $\mathrm{R}^{2} 0.44$; silt $\mathrm{R}^{2}$ 0.41; kum $\mathrm{R}^{2} \quad 0.29$; o.m $\mathrm{R}^{2} \quad 0.26$; kireç $\mathrm{R}^{2} 0.18$ olarak bulunmuştur. 201 yüzey ve yüzey altı toprağının kalibrasyon ve validasyon setlerine ayrilarak da değerlendirilmesi yapılmıştır (Çizelge 2). Buna göre, kalibrasyonun $\mathrm{R}^{2}$ değerleri sırasıyla; kil, 0.55; silt, 0.52; kum, 0.22; om, 0.10 ve kireç, 0.56 olarak görülmektedir. Tüm veri setine oranla yüzey topraklarının kalibrasyonunun RMSE değerleri bir miktar daha düşük bulunmuştur ancak yine de yüksek değerlere sahiptir. Ayrıca tüm veri setinde olduğu gibi, yüzey yansıma değerlerinin de SEC değerleri RMSE değerlerine yakın ve yüksektir.

Validasyon setinde ise durum, kalibrasyon seti ile benzerlik göstermektedir. Sırasıyla $\mathrm{R}^{2}$ değerleri; kil 0.46 , silt 0.43 , kum 0.10 , om 0.07 , kireç 0.51 dir. Tüm veri setinin doğruluğunun daha doğru sonuçlarla tahmin edilebilmesi için mevcut veri setinden 350 örnek kalibrasyon, geriye kalan 181 örnek ise tahmin (prediction) için kullanılmıştır (Çizelge 3.). Modelin kalibrasyonu için kullanılan veri setinin $\mathrm{R}^{2}$ değerleri sırasıyla; 
kil 0.48 , silt 0.49 , kum 0.33 , om 0.34 ve kireç 0.35 dir. Modelin kalibrasyonun RMSE ve SEC değerleri çapraz doğrulama sonucu elde edilen hata değerlerine benzer olup, yüksek bulunmuştur. Tahmin modelinin validasyon setinde ise durum çapraz doğrulama sonucu elde edilen $\mathrm{R}^{2}$ değerlerine benzerdir. Sirasıyla $\mathrm{R}^{2}$ değerleri; kil 0.45 , silt 0.45 , kum 0.28 , o.m 0.26 ve kireç 0.28 olarak bulunmuştur. RMSE ve SEC değerleri tıpkı çapraz doğrulamada olduğu gibi birbirine yakın ve küçük nüanslar dışında birbirine benzerdir.

201 Yüzey-yüzey altı örneği için de veri seti model oluşturmak amacıyla ikiye bölünmüştür (Çizelge 3.). Toprak örneklerinin 140 tanesi modelin kalibrasyon seti için, geriye kalan 61 tanesi ise tahmin amacıyla kullanılmıştır. Kalibrasyon için kullanılan 140 yüzey- yüzey altı örneğinin $\mathrm{R}^{2}$ değerleri; kil 0.55, silt, 0.52, kum 0.22 , o.m, 0.18 ve kireç 0.64 dür. Validasyon setinde ise $\mathrm{R}^{2}$, kil 0.46 , silt 0.43 , kum 0.10 , o.m 0.14 ve kireç 0.56 olarak bulunmuştur.

Her iki tahmin modeli arasında dikkate değer bir farklılık görülmemesine rağmen, tüm ve yüzey veri setleri içindeki örneklerin bir kısmının kalibrasyona ayırılarak değerlendirilen tahmin modellemesinin, diğerine göre biraz daha yüksek $\mathrm{R}^{2}$ ve daha düşük RMSE değerlerine sahip olduğu gözlemlenmektedir. Ancak hem veri setinin ayırt edilerek hem de birebir (çapraz) doğrulama yöntemi kullanılarak yapılan her iki tahmin için de elde edilen regresyon $\mathrm{R}^{2}$ değerleri yetersiz kalmıştır. Ayrıca her iki veri seti incelendiğinde (tüm ve yüzey altı) beş farklı toprak özelliği (kil, silt, kum, om, kireç) model içerisinde ilişki aranan yansıma değerleri ile iyi bir kalibrasyon gösterememiştir.

Yapılan tahminler 1şı̆̆ında, 531 toprak örneği için yansıma değerleri ölçülen değerler ile gerçek analiz değerleri arasında yüksek bir ilişkiye ulaşılamamıştır. Bunun nedenleri arasında; (i) çalışma alanının kısıtlı jeolojik yapısı ve heterojenliği (jeolojik formasyonun ayrılmamış kuvarteneryapıda olmas1),(ii) toprakörneklerinin mevcut kireç içeriklerinin yüksek olması ve diğer toprak özelliklerinin (o.m, kum, silt, kil) yansıma değerlerini olumsuz yönde etkilemesi ve (iii) eski toprak verilerinden oluşan analitik verilerin kullanılması sayılabilir. $\mathrm{Bu}$ çalışma, toprak etüd ve işlemleri sırasında toprakların daha gerçeğe yakın morfolojik gözlemlerin yanı sıra morfometrik ve nicel gözlemlerle desteklenmesi ve arazide hem uzman gereksinimini hem de harcanılan süreyi azaltacak yeni yaklaşımların keşfedilmesini amaçlamıştır. Ayrıca, toprak etüt ve arazi çalışmalarına entegrasyonu sağlanmaya çalışılmıştır. Bunlarla birlikte, II. Arazi çalışmaları sırasında tanımlaması yapılmış serilerin sınır kontrolleri aşamasında da etütçüye yardımcı olması hedeflenmiştir. Ancak her iki amaç için de spektroskopi aletinin arazi çalışmalarına entegrasyonu bu çalışmada başarıya ulaşamamıştır.

NIRS teknolojisi ile sinırlı alanda ve kısıtl sayıda örnek kullanılarak yapılan birçok çalışmada başarılı sonuçlara ulaşıldığı ileri sürülmektedir. Ancak, geniş alanlarda ve fazla sayıda örnekle yapılan bu çalışma beklenilen başarıya ulaşamamıştır. Gelecekte yapılacak çalışmaların, hem çalışma alanının sınırlarının 
genişletilmesi hem de birden çok değişken faktörü içeren geniş coğrafi alanlarda yeterli sayıda veri setini, uygun kalibrasyon ve modelleme yöntemleriyle destekleyerek istenilen sonuçlara ulaşılması üzerine odaklanılmalıdır. Ayrıca profil çukurları açılarak yerinde elde edilen yansıma değerleri ve kontrollü laboratuvar koşullarında yapılacak analizlerin entegrasyonu ile yansıma verileriyle daha yüksek kalibrasyon değerlerine ulaşılabilmesi için gelecek çalışmaların bu yönde yapılması daha doğru sonuçlar verebilir.

\section{AÇIKLAMA}

Çalışmanın yürütülmesi ve sonuçların yazılması esnasında araştırma ve yayın etiğine uyulmuştur. Herhangi bir "Çıkar Çatışması" bulunmamaktadır. Makalede yazarlar eşit oranda katkı sağlamıştır.

\section{KAYNAKLAR}

Anonim, 2016. Birleşmiş Milletler Ekonomik ve Sosyal İşler Dairesi Nüfus bölümü www. worldometers.info

Anonim, 2018. https://kadirnar.com/post/crossvalidationcapraz-dogrulama-nedir-verion-isleme/49

Ben-Dor, E., and Banin, A. 1995. Near infrared analysis (NIRA) as a method to simultaneously evaluate spectral featureless constituents in soils. Soil Sci. 159, 259-270

Bilgili, V., van Es, H., Akbash, F., Durak, A. and Hively, W. 2010. Visible-Near Infrared Reflectance Spectroscopy for Assessment of Soil Properties in a
Semi-Arid Area of Turkey.

Bogrekc1, I. and Lee, W.S. 2006. Transactions of the ASAE 49, 4, pp: 1175-1180

Brown, D. J., Shepherd, K. D., Walsh, M. G., Mays, M. D., and Reinsch, T. G. 2006. Global soil characterization withVNIRdiffuse reflectance spectroscopy. Geoderma 132, 273-290.

CAMO Inc. 1998. The Unscrambler user manual. CAMO Inc, Corvallis, OR.

Chang, C-W., Laird, D. 2002. Near-Infrared Reflectance Spectroscopy Analysis of Soil C and N. Soil Science, 167, 2, 110116.

Dinç. U., Schitchting E., Sarı. M., Şenol, S., Kapur, S., Sayın. M., Derici, R., Çavuşgil, V., Gök, M., Aydın, M., Ekinci, H., Ağca, N. 1995. "Çukurova Bölgesi Toprakları" 2.Baskı syf. 172. Adana

Günal, H., Erşahin, S., Akbaş, F. ve Budak, M., 2007. Toprak Biliminde Kızılötesi Spektrometrenin Potansiyel Kullanımı. Ondokuz Mayıs Üniv. Ziraat Fakültesi Dergisi, 22(2):219-226 Samsun

Hunt, G. R. 1977. Spectral signatures of particulate minerals in visible and nearinfrared. Trans. Am. Geophys. Union 58, 553.

Islam, K., Singh, B., and McBratney, A. 2003. Simultaneous estimation of several soil properties by ultra-violet, visible, and near-infrared reflectance spectroscopy. Aust. J. Soil Res. 41, 1101-1114.

Kılıç, E., Köseoğlu F. ve Yılmaz, H., 1998.

Enstrümental Analiz İlkeleri Bilim Yayınc1lık, Kızılay, Ankara.

Kuang, B. and Mouazen, A. M. (2011), 
Calibration of visible and near infrared spectroscopy for soil analysis at the field scale on three European farms. European Journal of Soil Science, 62: 629-636. doi:10.1111/j.1365-2389.2011.01358.x

Mouazen, A. M., Karoui, R., De Baerdemaeker, J., and Ramon, H. 2005. Classification of soil texture classes by using soil visual near infrared spectroscopy and factorial discriminant analysis techniques. J. Near Infrared Spectrosc. 13, 231-240.

Mouazen, A.M., R. Karoui, J. De Baerdemaeker, H. Ramon. 2006. Characterization of Soil Water Content Using Measured Visible and Near Infrared Spectra. Soil Sci. Soc. of Am. J. 70:1295-1302.

Norris, K.H. 1988. History, present state and future prospects f01 near-infrared spectroscopy. p. 3-9. In C.S. Creaser and A.M.CDavies (ed.) Analytical application of spectroscopy. R. Soc. Chem.London.

Özbek H, Dinç, U., Kapur, S., Güzel, N. 1974. Çukurova Üniversitesi Yerleşim Sahası Topraklarının Detaylı Etüd ve Haritalanması, Ankara Üniversitesi Basımevi, Ankara.

Pasquini, C., 2003. Near infrared spectroscopy: Fundamentals, practical aspects and analytical applications. J. Braz. Chem. Soc. Vol. 14:2, 198-219.

PANalytical, B.V, Boulder, Colorado, 2018. USA, Analytical Spectral, Devices, https://www.malvernpanalytical.com/ en/products/product-range/asd-range/ fieldspec-range

Rossel V, D.J.J. Walvoort, A.B. McBratney, L.J. Janik, J.O. Skjemstad, 2006. Visible, near infrared, mid infrared or combined diffuse reflectance spectroscopy for simultaneous assessment of various soil properties, Geoderma, Volume 131, Issues 1-2, Pages 59-75, ISSN 0016-7061.

Rossel V, R. A., and McBratney, A. B. 2008. Diffuse reflectance spectroscopy as a tool for digital soil mapping. In "Digital Soil Mapping with Limited Data" (Mc Bratney A. B. Hartemink AE and L. Mendonc,a-Santos, Eds.), Developments in Soil Science Series, Elsevier Science, Amsterdam

Stenberg B., Raphael A. Viscarra Rossel, Abdul Mounem Mouazen, and Johanna Wetterlind, 2010. Visible and Near Infrared Spectroscopy in Soil Science. In Donald L. Sparks, editor: Advances in Agronomy, Vol. 107, Burlington: Academic Press, pp. 163-215.

Turgut Y.Ş., 2019. Toprak Serilerinin Tanımlanması Ve Haritalanması Aşamasında NIRS (Near Infrared Spectroscopy) Yansıma Tekniğinin Kullanım Olanaklarının Çukurova Örneğinde Araştırılması, Çukurova Üniversitesi Fen Bilimleri Enstitüsü Toprak Bilimi ve Bitki Besleme Ana Bilim Dalı, Yüksek Lisans Tezi, 154 s.

Whalley, W. R., Leedsharrison, P. B., and Bowman, G. E. 1991. Estimation of soil-moisture status using near-infrared reflectance. Hydrol. Process. 5, 321-327. 